American Journal of Applied Sciences 6 (1): 13-23, 2009

ISSN 1546-9239

(C) 2009 Science Publications

\title{
Usage of Lightning Arrester Line to Feed Light Electrical Loads
}

\author{
${ }^{1}$ Hani Bani Odeh and ${ }^{2}$ Yousif El-Tous \\ ${ }^{1}$ Faculty of Engineering, Al-Tehadi University, Libya \\ ${ }^{2}$ Faculty of Engineering Technology, Al-Balqa Applied University, Jordan
}

\begin{abstract}
In remote areas, light loads (tens of kilowatts) are scattered and situated in the field of high voltage lines (66KV and above). These loads are very far from the main feeders/sub-stations (33KV$0.380 \mathrm{KV})$. Feeding such loads in the traditional ways like provision of Diesel-Powered Stations, installation of new distribution lines from the Feeding Centers, or building new Sub-Stations are not practical ways from the economical point of view, because it requires huge additional expenses and will increase electrical power losses. These expenses are not worthy for such loads and therefore, it is necessary to search for other methods to supply them. One of these methods is to use the lightning arrester line as capacitive divider to supply the light loads. In this research, the induced voltage of the lightning arrester line was calculated when it is isolated from the earth. We found the capacitance between lightning arrester line versus the phases and lightning arrester. It was also found the selective power out of the lightning arrester line and the required length which is to be isolated from the earth keeping the main function of the lightning arrester line. When economically comparing between supplying the light electrical loads by traditional ways and the method of lightning arrester, it was found the advantage of using lightning arresters to supply such loads. Also, by using the traditional methods, it was noted that there is a power loss in the power transmission lines by a percentage of $1.8 \%$.
\end{abstract}

Key words: Lightning arrester, loads, economics, high voltage lines, capacitive divider

\section{INTRODUCTION}

There are scattered loads everywhere which lay in the field of high voltage lines specially those is close (adjacent) to transportation roads like petrol stations, restaurants ... etc). Supplying these loads in the traditional methods is too expensive while these are only low power-consuming loads and lying in the field of high voltage lines (220KV and above) which are fed from substations $(220 / 0.4 \mathrm{KV})$. This will lead to the investment in big transformers but on the other hand, the complete power of these transformers is not utilized $^{[1]}$. Nowadays, the rating of power transformers which operates on $220 \mathrm{KV}$ is not less than $2.5 \mathrm{MW}$. Reducing the nominal power of these transformers based on the used power will cause an increase in the unit price (cost of one kilowatt compared to transformer cost). Therefore, we should search for new ways that are feasible from the economical point of view. (It should be noted the possibility of using Voltage Dividers to feed agricultural loads located within the High Voltage lines and far from the main Distribution Centers 11-0.38KV. Some Capacitive Dividers were used to feed the indication lamps at High Voltage lines crossing rivers and rough areas.

In the sixties of last century the use of such Dividers (to supply remote villages) appears in some American Scientific magazines and since then, no considerable developments were recorded in this field due to the lack of such subjects in the scientific libraries. In the other hand, most remote industrial areas were fed by electricity ${ }^{[1,2,3]}$.

During the construction of such plants, many problems faced those who were dealing with this subject, such as the possibility of having three phase Dividers, the possibility of lines protection during short Circuit at those power plants, the effect of these Dividers on the Network's operation and the resonance at some parts of the sub-station etc. All of the above factors slowed down the scientific researches on the voltage dividers.

In 1980, in the Scientific Research Center in Moscow, a single Phase Voltage Divider Station was built to supply the Train Indication lamps at the crosssection of Railway with roads, that station was called Capacitive Voltage Divider where Capacitors were used

Corresponding Author: Yousif El-Tous, Faculty of Engineering Technology, Al-Balqa Applied University, P.O.Box 331006, Amman 11134, Jordan, Tel: Fax: +962-6-5679773 
to divide the voltage. Since then, many scientific articles were discussing the possibility of using Voltage Dividers to feed the protection elements of electrical Networks and the possibility of building a special Reactor (Air Transformer) as a voltage Divider to feed some loads at country sides $)^{[4]}$.

This paper studies the possibility of using lightning arrester line as a source of power to such loads while keeping the main function of this arrester.

\section{CALCULATIONS OF INDUCED VOLTAGE AND CAPACITANCE BETWEEN THE HIGH VOLTAGE LINES AND LIGHTNING ARRESTER LINE}

As it is well known, lightning arrester line is always installed at the top of high voltage lines. It usually consists of single line or double lines depending on the operating voltage of the high voltage lines. Figure 1 shows two samples.

When hanging the lightning arrester line in the field of high voltage lines, it becomes a capacitive divider because there is capacitance between it and the high voltage lines from one side and the ground (earth) from the other side ${ }^{[5]}$.

While calculating the capacitive dividing stations, it is better to follow the computation in two stages:

First Stage: By means of the initial data and the voltage of high voltage line $\mathrm{U}_{1 . n}$, it is possible to determine the location of lightning arrester with reference to the high voltage lines as in Fig. 2 . Then by using the formulas in Table 1, we indicate the coefficients of voltage difference which represents the matrix $[\alpha]$. Also, by solving the set of Eq. 1 and 3 we indicate the nominal values for the electrical charges $\mathrm{q}_{1}$, $\mathrm{q}_{2}, \mathrm{q}_{3}$.

In order to find the induced voltage on the lightning arrester line by the Mirror Reflection Method, considering that the induced voltage on the lightning arrester line is the linear voltage, it could be found as a result of the mutual affect between all the lines as follows ${ }^{[6]}$ :

$$
[\mathrm{U}]=[\alpha] \cdot[\mathrm{q}
$$

Where: $[\alpha]=$ Matrix of voltage coefficients

$[q]=$ Vertical matrix of linear charges

We symbolize the voltage self coefficients as $\alpha_{n n}$ and the reciprocal as $\alpha_{n m}$. They could be found as follows:

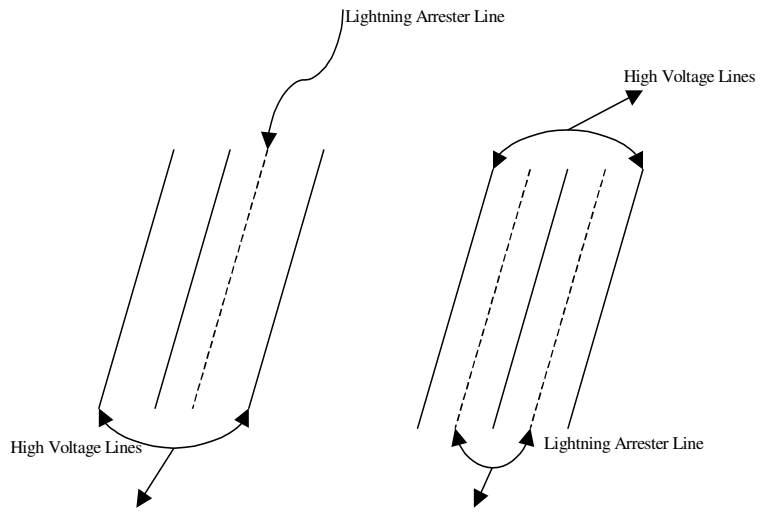

Fig. 1: Represents two samples of lightning arresters (A) quadruple system (B) quintuple system

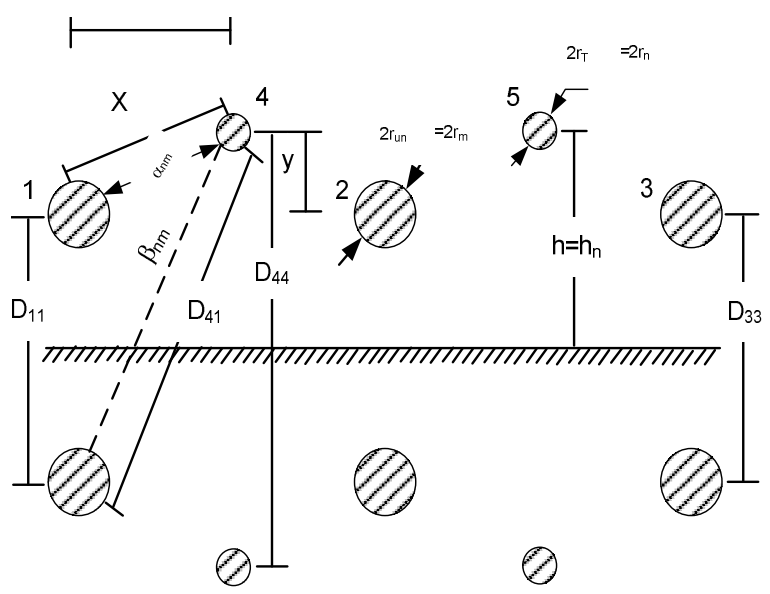

Fig. 2: Lines position and their imaginary shapes inside ground surface

Table 1: Equations for calculating voltage coefficients

$$
\begin{aligned}
& \alpha_{11}=\alpha_{22}=\alpha_{33}=K \cdot \operatorname{Ln} \frac{D}{r_{u n}}=K \cdot \ln \frac{2 h_{B}}{r_{u n}} \\
& \alpha_{44}=\alpha_{55}=K \cdot \ln \frac{2 h+2 x}{r_{T}} \\
& \alpha_{41}=\alpha_{53}=\alpha_{42}=\alpha_{52}=K \cdot \ln \frac{\sqrt{\left(2 h_{B}+\mathrm{X}\right)^{2}+y^{2}}}{\sqrt{\mathrm{x}^{2}+y^{2}}} \\
& \alpha_{43}=\alpha_{51}=K \cdot \ln \sqrt{\left(2 \mathrm{~h}_{\mathrm{B}}+\mathrm{X}\right)^{2}+\mathrm{y}^{2}} \\
& \mathrm{X}_{12}=\mathrm{X}_{23}=\mathrm{K} \cdot \ln \sqrt{\mathrm{X}^{2}+3 \mathrm{y}^{2}} \\
& \mathrm{X}_{45}=\mathrm{K} \cdot \ln \frac{\sqrt{\left(2 \mathrm{X}+2 \mathrm{~h}_{\mathrm{B}}\right)^{2}+\mathrm{y}^{2}}}{2 \mathrm{y}} \\
& \mathrm{X}_{13}=\mathrm{K} \cdot \ln \frac{\sqrt{2 \mathrm{~h}_{\mathrm{B}^{2}}+2 \mathrm{y}^{2}}}{2 \mathrm{y}}
\end{aligned}
$$

Where: $\mathrm{K}=$ const $=2.3 \times 10^{5}$

$$
\begin{aligned}
& \alpha_{n n}=K_{e q} \cdot \ln \frac{2 h_{n}}{r_{n}} \\
& \alpha_{n m}=K_{e q} \cdot \ln \frac{B_{n m}}{a_{n m}}
\end{aligned}
$$


Am. J. Applied Sci., 6 (1): 13-23, 2009

where, $\mathrm{K}_{\mathrm{eq}}=$ Electrostatic coefficient and it equals $18.10^{6} \mathrm{~km} / \mathrm{F}$.

$\mathrm{R}_{\mathrm{n}}=$ Radius of line $\mathrm{n}$.

$\mathrm{h}_{\mathrm{n}}=$ Height of line $\mathrm{n}$ hanging from earth surface

$\alpha_{\mathrm{nm}}=$ Distance between the lines $\mathrm{n}, \mathrm{m}$.

$\beta_{\mathrm{nm}}=$ Distance between line $\mathrm{n}$ and the reflection of line $\mathrm{m}$ on the earth.

Equation (1) is hard to be solved because it has two variables, therefore, we should select a way to solve, which allows ignoring some variables.

For example, when splitting (disconnect) the load from the lightning arrester which is isolated from the ground then the induced charges on the lightning arrester (single or double lines):

$$
\mathrm{q}_{4}=\mathrm{q}_{5}=0
$$

It is considered that the induced voltage on the lightning arrester lines will be equal if it is more than one line ${ }^{[7]}$.

On the basis of ignoring the previous variables, it is possible to write equation (1) as follows:

$$
[\mathrm{U}]=[\alpha] \cdot[\mathrm{q}]
$$

where,

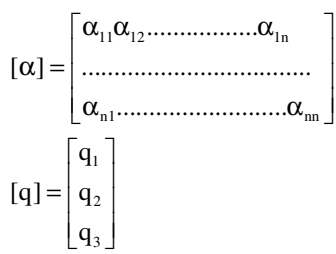

The calculations which have been done and the laboratory voltage divider (practically) shows that induced voltage on the two lines of lightning arrester $\mathrm{U}_{4}, \mathrm{U}_{5}$ is the same.

Second Stage: Specify the length of lightning arrester line from the following formula ${ }^{[6]}$ :

$$
\mathrm{La}=\frac{\mathrm{S}_{\mathrm{o} . \mathrm{F}}}{\omega \cdot \mathrm{C}_{\mathrm{yj}} \mathrm{U}_{\mathrm{AX}} \cdot\left(\sqrt{\mathrm{U}_{\mathrm{Tr}}\left(\mathrm{U}_{\mathrm{A}}-\mathrm{U}_{\mathrm{Tr}}\right)}\right)}
$$

Where, $\mathrm{C}_{\mathrm{yj}}=$ Type capacitance for the lightning arrester.

$\mathrm{U}_{\mathrm{AX}}=$ Induced voltage on the lightning arrester line. Then, we specify the partial capacitance of the upper arm for the divider.

$$
\mathrm{C}_{1}=\mathrm{La} \cdot \mathrm{C}_{\mathrm{nm}}
$$

From Eq. 3, it becomes obvious that in order to reduce the length of the lightning arrester, we should select a normal transformer with a relatively high nominal voltage to increase the capacitance type for lightning arrester line.

Also, when increasing the voltage of potential line, this will severely decrease the required length of the lightning arrester which should be isolated.

It is possible to find out the capacitances of the voltage capacitive divider by means of the lightning arrester as follows:

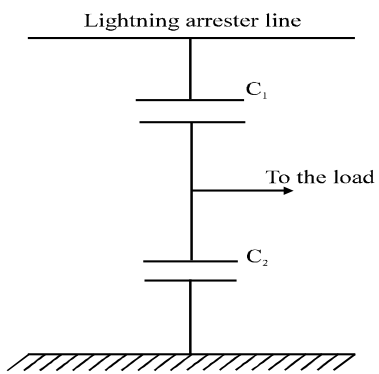

Capacitance of the below arm for the divider:

$$
\mathrm{C}_{2}=\mathrm{C}_{\mathrm{eq}}-\mathrm{C}_{1}
$$

This capacitance could be achieved by connecting several static capacitors, then the total capacitance of the below arm of the divider will be:

$$
\mathrm{C}_{2}=\mathrm{C}_{\mathrm{K}}+\mathrm{C}_{\mathrm{AA}}+\mathrm{C}_{\mathrm{L}}
$$

Where, $\mathrm{C}_{\mathrm{k}}=$ Capacitance of static capacitors.

$$
\begin{aligned}
\mathrm{C}_{\mathrm{AA}}= & \text { Capacitance of the potential line / } \\
& \text { Lightning arrester with respect to } \\
& \text { ground. } \\
\mathrm{C}_{\mathrm{L}}= & \text { Capacitance of connecting line. } \\
\mathrm{C}_{\mathrm{nn}}= & \text { Line capacitance / lightning arrester are } \\
& \text { usually known from the initial } \\
& \text { calculations, then from equation (4) you } \\
& \text { can specify: }
\end{aligned}
$$

$$
\mathrm{C}_{\mathrm{AA}}=\mathrm{L}_{\mathrm{A}} \cdot \mathrm{C}_{\mathrm{nn}}
$$

Where, $\mathrm{L}_{\mathrm{A}}=$ Length of lightning arrester line which should be isolated from the towers.

$\mathrm{C}_{\mathrm{nn}}=$ Type capacitance for lightning arrester lines with respect to ground.

While for the capacitance of the static capacitors, it could be found from the following formula: 
Table 2: Shows the Permissible Distance between the Arrester which is able to be Isolated from the High Voltage Line

\begin{tabular}{llllllll}
\hline $\mathrm{uL}, \mathrm{kv}$ & 110 & 220 & 330 & 400 & 500 & 750 & 1150 \\
Mono Circuit d ; M & 1.5 & 2 & 2.5 & 3 & 3.3 & 4.5 & 6.5 \\
Dual Circuit d ;M & $2.5-3$ & $3-3.5$ & $4-4.5$ & $4.5-5$ & 5.5 & 6.5 & $\ldots \ldots$ \\
\hline
\end{tabular}

$$
\mathrm{C}_{\mathrm{K}}=\mathrm{C}_{2}-\mathrm{C}_{\mathrm{AA}}-\mathrm{C}_{\mathrm{L}}
$$

Final length of lightning arrester line which is able to be isolated from the towers could be found by the following formula:

$$
\mathrm{L}_{\text {max }}=\mathrm{K}_{\mathrm{eq}}\left(\mathrm{C}_{\mathrm{eq}}-\mathrm{C}_{\mathrm{AA}}\right) \cdot \ln \frac{2 \mathrm{~h}}{\mathrm{r}}
$$

Where, $\mathrm{h}=$ Height of arrester line from the ground.

$$
\mathrm{r}=\text { Radius of the conductor. }
$$

$\mathrm{L}_{\max }$ is considered as the maximum value for the length of arrester line and if it exceeds this limit, a fault will occur in the preparations of the voltage divider.

It is important to point here that it is totally forbidden to make arrester lines closer or farther from the high voltage lines as this will increase or decrease the applied voltage on the arrester line. Based on what is mentioned above, a study have been carried out in order to specify the displacements between the arrester and the phases of high voltage lines, Table 2 shows that $^{[7]}$.

When finding the operating capacitances, we should find the partial capacitances first for the quadruple or quintuple line system, Fig. 3. Then we collect them all in a particular shape so that we will get a simplified shape.

Capacitance between the lines is determined by the engineering coefficients and the electrical susceptibility/penetrability on the surrounding environment.

The operating capacities are better to be found as per the following Series:

We can find the capacitance without considering the self capacitance of the lines by the following equation:

$$
C_{n m}=C_{n m}+\sum_{i=1}^{5}\left(\frac{C_{i n} C_{i m}}{C_{i n}+C_{i m}}-\frac{C_{n n} C_{n m}}{C_{n n}+C_{n m}}-\frac{C_{n m} C_{n m}}{C_{n m}+C_{m n}}\right)
$$

Where: Cin, Cnm, Cim, Cnn representing the partial capacitances of the lines.

to find the self capacitances of the lines;

$$
\mathrm{C}_{\mathrm{nn}}=\sum_{\mathrm{i}=1}^{5} \mathrm{C}_{\text {in }}^{-}
$$

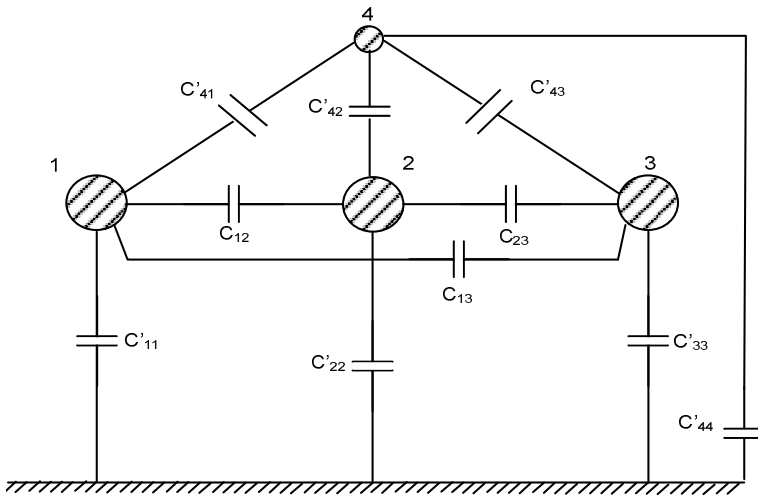

Fig. 3a: Partial capacitances for a quadruple lines system

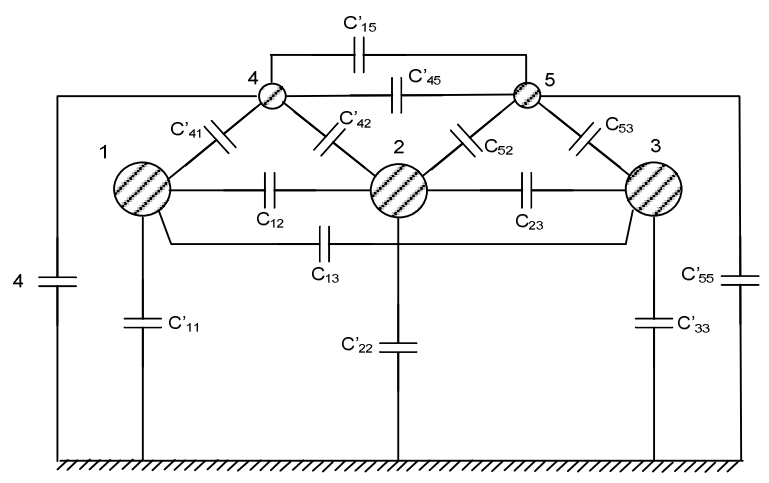

Fig. 3b: Partial capacitances for a quintuple lines system

We find out the capacitance considering the self capacitances of the lines:

$$
\mathrm{C}_{\mathrm{nm}}=\mathrm{C}_{\mathrm{nm}}+\frac{\mathrm{C}_{\mathrm{nn}} \cdot \mathrm{C}_{\mathrm{mm}}}{\mathrm{C}_{\mathrm{nn}}+\mathrm{C}_{\mathrm{mm}}}
$$

If we consider that the partial capacitances could be found through the determinant and algebraic addition to the matrix of voltage coefficients and for the purpose of calculating the operating capacitances, the formulas (10, 11 and 12) could take the following shape:

$$
\begin{gathered}
\mathrm{C}_{\mathrm{nn}}=\frac{1}{\Delta \mathrm{K}_{\mathrm{eq}}} \cdot \sum_{\mathrm{i}=1}^{5} \Delta_{\mathrm{in}} \\
\mathrm{C}_{\mathrm{nm}}=\frac{1}{\Delta \mathrm{K}_{\mathrm{eq}}}\left[\begin{array}{l}
\Delta_{\mathrm{nm}}+\sum_{\mathrm{i}=1}^{5}\left(\frac{\Delta_{\mathrm{in}} \Delta_{\mathrm{im}}}{\Delta_{\mathrm{in}}+\Delta_{\mathrm{im}}}-\frac{\Delta_{\mathrm{nn}} \Delta_{\mathrm{nm}}}{\Delta_{\mathrm{nn}}+\Delta_{\mathrm{nm}}}-\frac{\Delta_{\mathrm{mm}} \Delta_{\mathrm{mn}}}{\Delta_{\mathrm{mm}}+\Delta_{\mathrm{mn}}}\right) \\
+\left(\sum_{\mathrm{i}=1}^{5} \Delta_{\mathrm{in}} \cdot \sum_{\mathrm{i}=1}^{5} \Delta_{\mathrm{im}}\right) /\left(\sum_{\mathrm{i}=1}^{5} \Delta_{\mathrm{in}}+\sum_{\mathrm{i}=1}^{5} \Delta_{\mathrm{im}}\right)
\end{array}\right]
\end{gathered}
$$


Am. J. Applied Sci., 6 (1): 13-23, 2009

Where, $\Delta=$ is the main determinant which is formed from the voltage coefficients for a group of equations.

$$
[\mathrm{U}]=[\alpha] \cdot[\mathrm{q}]
$$

Where, $[U]=$ Matrix of phase voltage for a quintuple or quadruple line system.

Then $\Delta=|[\alpha]|$

While $\Delta_{\mathrm{nm}}=$ Algebraic addition.

$\mathrm{K}_{\mathrm{eq}}=$ Static coefficient.

Our concern in this study is to find the capacitances between the high voltage lines and lightning arrester lines: $\mathrm{C}_{14}, \mathrm{C}_{25}$ and the self capacitances of the arrester $\mathrm{C}_{44}, \mathrm{C}_{55}$.

Based on what is mentioned previously, it is clear that the possibility for calculating the capacitance between the lightning arrester and high voltage lines and the exposed voltage on the lightning arrester caused by the inductance when isolating the arrester from the ground for a distance could be determined by the required voltage and the amount of load power and operating voltage of the high voltage lines. If we could use this method (voltage dividing by means of the lightning arrester) to supply the country loads, then this method will be considered as one of the less expensive ways and consequently one of the highest for the economical pointers.

According to the previous relations, it is possible to specify the applied voltage on the lightning arrester line when it is isolated from the ground by the following formula:

$$
\grave{\mathrm{U}}_{\mathrm{TP}}=\frac{\grave{\mathrm{U}} \cdot \mathrm{C}_{\mathrm{ATP}}+\grave{\mathrm{U}}_{\mathrm{B}} \cdot \mathrm{C}_{\mathrm{BTP}}+\grave{\mathrm{U}}_{\mathrm{C}} \cdot \mathrm{C}_{\mathrm{CTP}}}{\mathrm{C}_{\mathrm{eq}}}
$$

Where, ÙA, ÙB, ÙC = The nodal voltage for the phases of high voltage lines consequently (A, B, C).

$\mathrm{C}_{\mathrm{ATP}}, \mathrm{C}_{\mathrm{BTP}}, \mathrm{C}_{\mathrm{CTP}}=$ Mutual type capacitance between the line of lightning arrester and the phases of high voltage lines.

Figure 4 represents the power that could be selected from the high voltage lines by means of the divider of lightning arrester. As seen from the figure, the selected power from the high voltage lines of the $500 \mathrm{KV}$ is less than the power which could be selected from the lines of the 330 and 220 voltages.

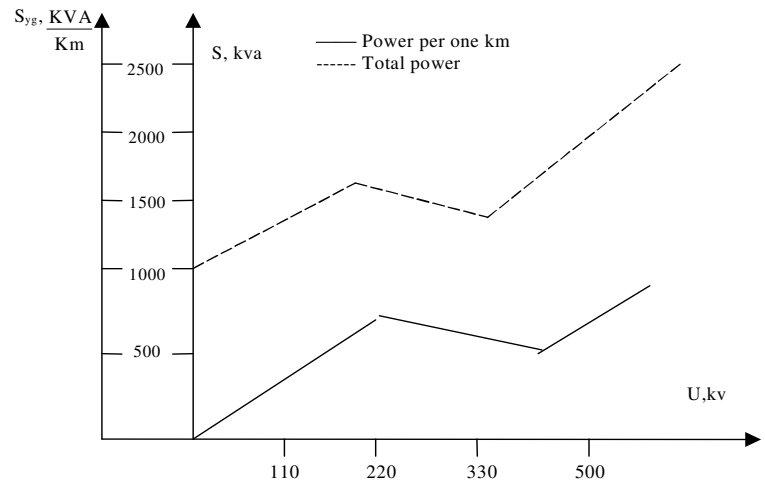

Fig. 4: Selected power from the high voltage lines by means of the capacitive divider and using the lightning arrester line as a divider

The reason for this is the position of lightning arrester lines with respect to the operating lines of high voltage.

Since calculating the voltage drop at the lightning arrester line and calculating the operating and self capacitances require complex calculations, the following serial method is to be followed:

- The line hanging between two towers is replaced by equivalent conductor in the shape of a straight line (Fig. 5B). This replacement is done by means of the curve (Fig. 5A), where at the $\mathrm{X}$-axis is the ratio of the conductor sagging $(\mathrm{f} / \mathrm{h})$ while at the $\mathrm{Y}$ axis is the measurement ratio of $(\mathrm{b} / \mathrm{fm})$. This is positioned to determine the location of straight equivalent line.

- The imaginary point of the operating conductors and of the lightning arrester line is drawn as in (Fig. 6c), then the following values are calculated:

1. The algebraic mean value of the distances between the high voltage lines and their imaginary images (locations) inside the earth.

$$
\mathrm{D}_{11 \mathrm{~m}}=\sqrt[3]{\mathrm{D}_{11} \mathrm{D}_{22} \mathrm{D}_{33}}
$$

2. The algebraic mean value of the distance between the lines and the imaginary points.

$$
D_{12 m}=\sqrt[3]{D_{12} \cdot D_{13} \cdot D_{23}}
$$

3. The algebraic mean value of the distance between the lines.

$$
d_{12 m}=\sqrt[3]{d_{12} \cdot d_{13} \cdot d_{23}}
$$



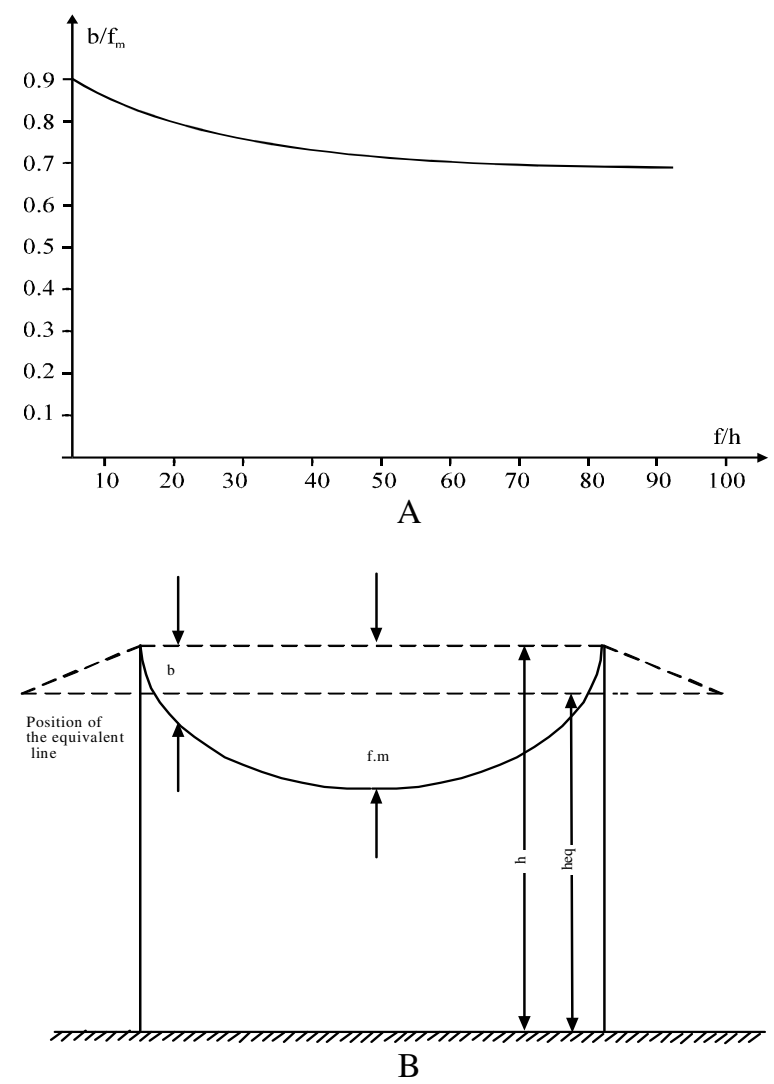

Fig. 5: Replacement of the tension line by its equivalent (A) Relation between the ratio $\mathrm{b} / \mathrm{f}_{\mathrm{m}} \&$ the ratio $\mathrm{f} / \mathrm{h}$. (B) Diagram of the tension line position

4. The voltage applied on the lightning arrester line is determined by the following formula:

$$
\frac{\mathrm{L}_{\mathrm{g}} \frac{\mathrm{D}_{41}^{2} \cdot \mathrm{d}_{42} \cdot \mathrm{d}_{43}}{\mathrm{D}_{41}^{2} \cdot \mathrm{D}_{42} \cdot \mathrm{D}_{43}}+\mathrm{j} \sqrt{3} \mathrm{Lg} \frac{\mathrm{D}_{42} \cdot \mathrm{d}_{43}}{\mathrm{~d}_{42} \cdot \mathrm{D}_{43}}}{2 \mathrm{Lg} \frac{\mathrm{D}_{11 \mathrm{~m}} \cdot \mathrm{d}_{12 \mathrm{~m}}}{\mathrm{r}_{\mathrm{TP}} \cdot \mathrm{D}_{12 \mathrm{~m}}}}
$$

5. The equivalent capacitance for every kilometer of the line or the lightning arrester is determined by:

$$
\begin{aligned}
\mathrm{C}_{\mathrm{eq}}= & \frac{(\mathrm{B}+2 \mathrm{~b})(\mathrm{B}-\mathrm{b})}{18\left(\alpha_{44}(\mathrm{~B}+2 \mathrm{~b})(\mathrm{B}-\mathrm{b})-\mathrm{B}\left(\alpha^{2}{ }_{41}+\alpha_{42}+\alpha_{43}\right)\right.} \\
\mathrm{B} & =2.3 .10^{6} \ln \frac{\mathrm{D}_{11}}{\mathrm{r}_{\mathrm{un}}} \\
\mathrm{b} & =2.3 .10^{6} \ln \frac{\mathrm{D}_{12 \mathrm{~m}}}{\mathrm{~d}_{12 \mathrm{~m}}}
\end{aligned}
$$

Where, $r_{u n}=$ radius of the conductor in meter.

$$
\begin{aligned}
& \alpha_{\text {in }}=2.3 \cdot 10^{6} \log \frac{D_{\text {in }}}{d_{\text {in }}} \\
& \alpha_{\text {nn }}=2.3 \cdot 10^{6} \log \frac{D_{\text {mn }}}{r_{\text {TP }}}
\end{aligned}
$$

$\mathrm{r}_{\mathrm{TP}}=$ radius of the lightning arrester line.

\section{ECONOMICAL COMPARISON OF THE METHODS FOR FEEDING DIFFERENT ELECTRICAL LOADS}

Basically, when comparing between two possibilities or more in the electrical systems, there are two important factors for comparison:

- Economical Factor, Quality and Reliability Factor in the work. Since all possibilities don't have the same level of reliability, the physical damage that will occur on the electrical and economical system should be considered when there is a power failure.

Since the damage which can occur caused by power failure on the single load through the substations or voltage dividers will be one, therefore, it is not considered in the calculation.

In this study, the known rules in the economical comparison between methods of feeding electrical loads were used, whether the traditional ones (substations, main feeding centers, direct over head lines) or the proposed method by means of the voltage dividers. The comparison by means of the converted expenses, basic capital and running expenses, was used.

$$
\zeta_{\mathrm{i}}=\mathrm{P}_{\mathrm{n}} \cdot \mathrm{K}_{\mathrm{i}}+\mathrm{C}_{\mathrm{i}}
$$

$$
\text { Where, } \begin{aligned}
\mathrm{P}_{\mathrm{n}} & =\begin{array}{l}
\text { Coefficient of basic } \\
\text { performance. }
\end{array} \\
\mathrm{K}_{\mathrm{i}} & =\begin{array}{l}
\text { Expenses of basic capital for the } \mathrm{i} \\
\text { possibility }
\end{array} \\
\mathrm{C}_{\mathrm{i}} & =\text { Yearly Investment expenses }
\end{aligned}
$$

Preference of selecting the loads i for which the expenses $\zeta_{\mathrm{i}}$ is the least between the possibilities when calculating the main expense for building electrical systems in the country areas. We should consider the additional expenses to generate electrical energy in order to compensate the electrical losses. If the country loads (small ones)the main feeding centers are supplied from ,then the basic capital can be calculated as follows:

$$
\mathrm{K}=\sum \mathrm{K}_{\mathrm{L}}+\mathrm{K}_{\mathrm{st}}+\mathrm{K}_{\mathrm{p}}+\mathrm{K}_{\mathrm{g}}
$$


Am. J. Applied Sci., 6 (1): 13-23, 2009

Where, $\Sigma \mathrm{K}_{\mathrm{L}}=$ Summation of basic expenses on the power lines.

$\Sigma \mathrm{K}_{\mathrm{ST}}=$ Summation of basic expenses on the substations.

$\mathrm{K}_{\mathrm{p}}=$ Expenses of distribution and protection components.

$\mathrm{Kg}=$ Basic expenses related to energy losses. The additional losses can be calculated from the following formula:

$$
\mathrm{K}_{\mathrm{g}}=\alpha\left(\sum \mathrm{P}_{\mathrm{L}}+\sum \Delta \mathrm{P}_{\mathrm{st}}\right.
$$

Where, $\alpha=$ Fixed algebraic coefficient equals $70^{\mathrm{D} / \mathrm{KW}}$.

$\mathrm{K}_{\mathrm{L}}, \mathrm{K}_{\mathrm{st}}=$ It could be taken from the catalogue or from planning establishments for electrical systems.

If the small loads are fed from a diesel station then the basic expenses could be calculated as follows:

$$
\mathrm{K}_{\text {darel }}=\mathrm{K}_{\mathrm{st}}+\mathrm{K}_{\mathrm{T} . \mathrm{st}}+\mathrm{K}_{\mathrm{T} . \mathrm{x}}+\mathrm{K}_{\mathrm{L}}
$$

Where, $\mathrm{K}_{\mathrm{st}}=$ Expenses on building the station (cost of machines + the building itself)

$\mathrm{K}_{\mathrm{T} . \mathrm{ST}}=$ Cost of substation (stepping up the voltage)

$\mathrm{K}_{\mathrm{T} . \mathrm{X}}=$ Expenses for building the fuel tanks.

$\mathrm{K}_{\mathrm{L}}=$ Expenses for building the distribution lines.

There are some loads which are very far, or in other words these loads are farther than the economical radius from the main feeding centers, therefore, we should use the diesel station for supplying such loads. Sometimes, these diesel stations are used as a spare source to supply the loads with electrical energy. The reason for this is due to the load income of these stations and due to the extra investment expenses ${ }^{[5]}$.

The yearly investment expenses which enter in the transferred expenses in relation (21) when supplying the loads from the main feeding centers consist of the expenses of machine foundations and maintenance of all the machines and lines. We could determine these expenses from the following relation:

$$
\begin{aligned}
& \mathrm{C}_{\text {eL.st }}=\sum_{\mathrm{i}=1}^{\mathrm{i}=1} \mathrm{~K}_{\mathrm{Li}} \frac{\mathrm{P}_{\mathrm{ai}} \mathrm{P}_{\text {tr.i }}}{100}+\sum_{\mathrm{i}=1}^{\mathrm{i}=1} \mathrm{~K}_{\mathrm{SA} . \mathrm{T}} \frac{\mathrm{P}_{\mathrm{ai}}^{\prime}+\mathrm{P}_{\text {tr.i }}^{\prime}}{100} \\
& +\mathrm{K}_{\mathrm{P}} \frac{\mathrm{P}_{\mathrm{ai}}+\mathrm{P}_{\text {tr. }}}{100}+\beta \cdot\left(\sum \Delta \mathrm{A}\right)+\mathrm{M}
\end{aligned}
$$

Where: $\mathrm{P}_{\mathrm{ai}}, \mathrm{P}_{\mathrm{tr} . \mathrm{i}},=$ Partial expenses (in percentage) on the foundation and maintenance of tension lines.

$$
\begin{aligned}
& \mathrm{P}_{\text {ai }}^{\prime}, \mathrm{P}_{\text {tri. }}^{\prime}=\begin{array}{l}
\text { Partial expenses on the } \\
\text { substations. }
\end{array} \\
& \begin{array}{ll}
\mathrm{P}_{\text {ai }}^{\prime \prime}, \mathrm{P}_{\text {tr. }}^{\prime \prime}= & \begin{array}{l}
\text { Partial expenses on the protection } \\
\text { and distribution equipment. }
\end{array} \\
\beta \quad= \\
=\begin{array}{l}
\text { Cost of kilowatt hour from the } \\
\text { electrical losses. }
\end{array}
\end{array}
\end{aligned}
$$

$$
\Sigma \Delta \mathrm{A}=\Sigma \Delta \mathrm{A}_{\mathrm{L}}+\Sigma \Delta \mathrm{A}_{\mathrm{st} . \mathrm{T}}+\mathrm{A}_{\mathrm{C} . \mathrm{H}}
$$

Where, $\Delta \mathrm{A}_{\text {st. } \mathrm{T}}, \Delta \mathrm{A}_{\mathrm{L}}=$ Electrical losses on the lines and substations.

$\mathrm{A}_{\mathrm{C} . \mathrm{H}}=$ Consumed energy in the substation's self-works.

$\mathrm{M} \quad=$ Expenses on manpower.

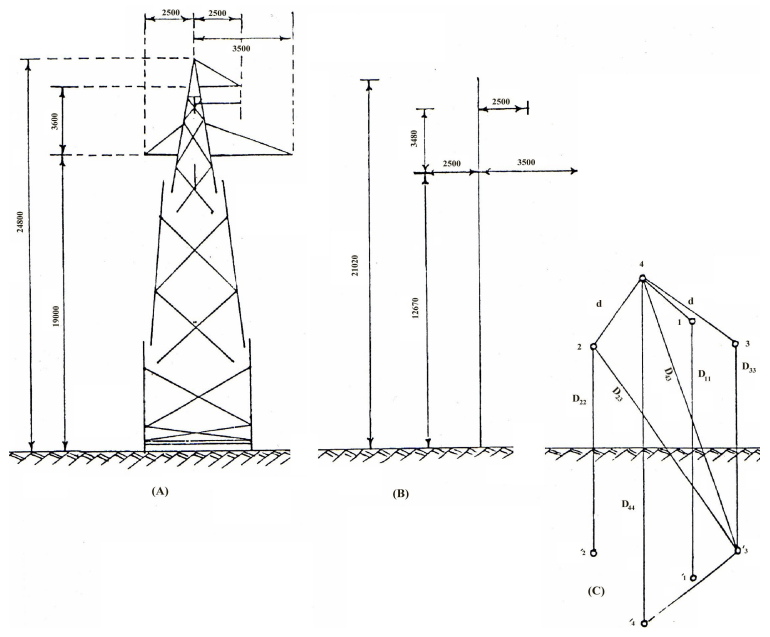

Fig. 6

The cost of electrical loads fed from the main substation can be calculated through the following formula:

$$
\mathrm{C}_{\text {d.el.st }}=\mathrm{K}_{\text {d.el.st }} \frac{\mathrm{P}_{\mathrm{a}}+\mathrm{P}_{\mathrm{t.r}}}{100}+\mathrm{N}+\mathrm{M}+\beta . \mathrm{A}_{\mathrm{C} . \mathrm{H}}
$$

Where:

$\mathrm{N}=\mathrm{Q} . \lambda-$ Yearly expenses on fuel.

$\mathrm{Q}=$ Yearly fuel quantity.

$\lambda=$ Cost of one tone of fuel.

We can determine the cost of electrical energy for the electrical loads supplied by the main stations from the following relation:

$$
\delta_{\text {el.st }}=\frac{C_{\text {el.st }}}{A_{r}}
$$

For other loads supplied by diesel stations, the cost can be determined from the following law: 
Am. J. Applied Sci., 6 (1): 13-23, 2009

$$
\delta_{\text {d:el:st }}=\frac{C_{\text {deelst }}}{A_{n}}
$$

From the previous relations, it is obvious that in order to get $\delta_{\text {el.st }}$ and $\delta_{\text {d:el:st }}$ the least, we should select the loads having the expenses $\zeta_{\mathrm{i}}$ in relation (21).

In this study, a comparison has been done between supplying the small loads from the main feeding centers by means of high voltage lines and substations and supplying the loads by means of diesel stations or partitioning stations.

We have illustrated in Fig. 7 the drawing representing the relation between the Capital and the unitary expenses (Capital for one unit) and the required power to supply the country loads (small ones).

We can see that increasing the required power for the load, increases the basic expenses. Also, we can see that when there is a low power load, the unitary expenses will be high.

This relation has been put for the loads that are supplied from main feeding sources by means of the tension lines and lies at a bigger distance than its economical diameter.

We have illustrated in Fig. 8 the drawings which explain the relation between the basic expenses and the unity for diesel stations in relation to the station power. From the figure we see that when we increase the station power, its cost will increase consequently. Also, we can see that when supplying the small loads from these stations, this will lead to the increase of unity expenses (i.e. Cost of Kilowatt hour). These drawings could be utilized when planning the electrical networks in the Republic.

While for the voltage dividers, the basic expenses for such stations could be determined as per the following relation:

$$
\mathrm{K}_{\pi}=\mathrm{K}_{\mathrm{d}}+\mathrm{K}_{\mathrm{K}}+\mathrm{K}_{\mathrm{T}}-\lambda \mathrm{K}^{\prime} \pm \mathrm{K}_{\mathrm{Q}}
$$

Where,

$$
\begin{aligned}
\mathrm{K}_{\mathrm{d}}= & \text { Cost of voltage divider. } \\
\mathrm{K}_{\mathrm{K}}= & \text { Cost of both power compensator. } \\
\mathrm{K}_{\mathrm{T}}= & \text { Cost of normal transformer (voltage step } \\
& \text { down). } \\
\mathrm{K}= & \text { Cost of elements used to select the } \\
\text { energy and at the same time using the } & \text { high voltage lines. } \\
\Lambda= & \begin{array}{l}
\text { Constant coefficient depends on } \\
\text { compensation element. }
\end{array} \\
\mathrm{K}_{\mathrm{Q}}= & \begin{array}{l}
\text { Cost of Reactive power in the voltage } \\
\text { dividers. }
\end{array}
\end{aligned}
$$

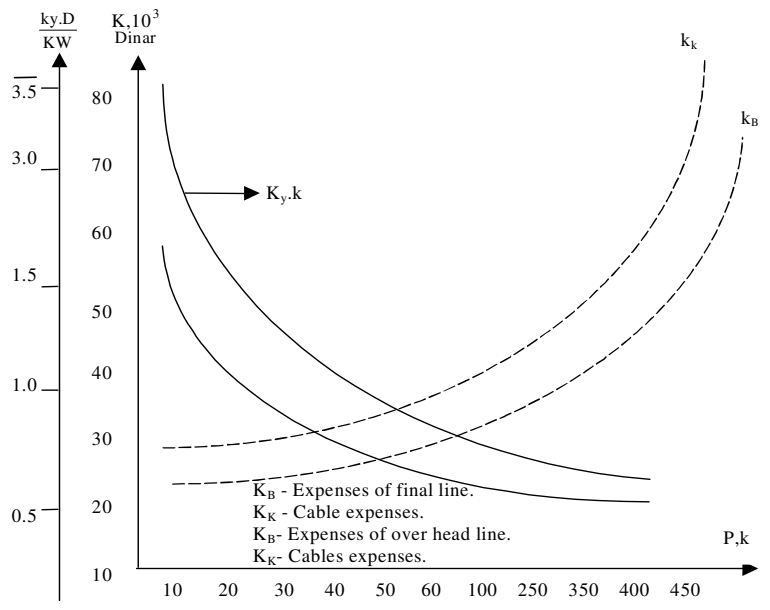

Fig. 7: Relation between the basic Capital, the unity expenses and the required power to supply the country loads (small ones)

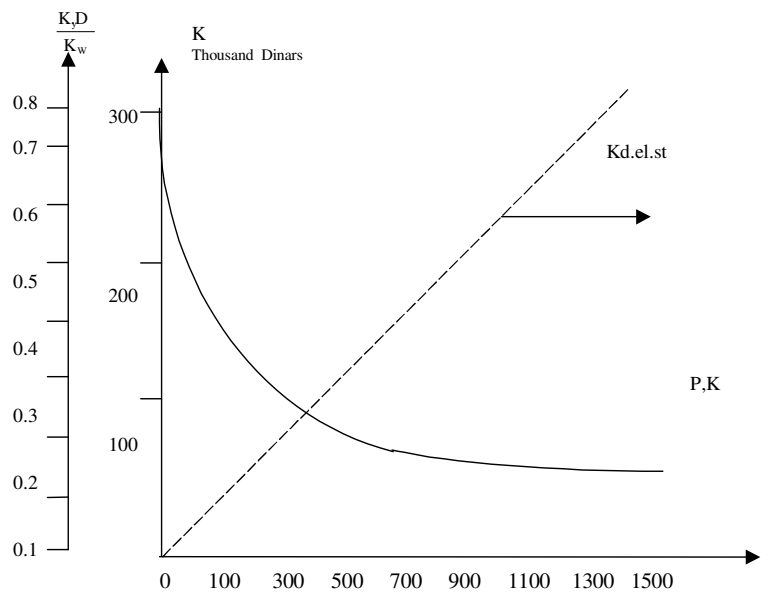

Fig. 8: Relation between basic expenses and unity expenses for diesel stations in relation to the required power

As it is clear in equation (29), we can see that the basic cost for selecting the energy depends on the selected power and on the coefficient of voltage dividers.

$$
\mathrm{K}_{\lambda}=\mathrm{f}\left(\mathrm{S}, \mathrm{K}_{\mathrm{d}}\right)
$$

Where: $K_{d}$ - Depends on the phase voltage at the point where the divider is connected. $K_{d}$ should be chosen in a way that the deviation in the voltage value does not exceed $\pm 5 \%$. Therefore, in general, we can determine the coefficient of voltage division as follows: 
Am. J. Applied Sci., 6 (1): 13-23, 2009

$$
\mathrm{K}_{\mathrm{d}}=\frac{\mathrm{U}_{\mathrm{n}}}{\mathrm{U}_{\mathrm{eq}}}=\frac{\mathrm{U}_{\mathrm{n}} \cdot \Delta \mathrm{U}}{\mathrm{U}_{\mathrm{eq}}}
$$

Where: $\mathrm{Un}=$ The voltage at the point of hanging the divider and equals the phase voltage.

Ueq $=$ The equivalent voltage and it takes the amount of input voltage of the transformer.

It is possible to write the equation of Total Expenses in the circuit of voltage dividers as follows:

$$
\begin{aligned}
\mathrm{K}_{\pi}= & 2 \sqrt{\mathrm{K}_{\mathrm{d}}-1} \mathrm{~S} \cdot \mathrm{C}_{\mathrm{d}}+\sqrt{\mathrm{K}_{\mathrm{d}}-1} \mathrm{~S} \cdot \mathrm{C}_{\mathrm{K}}+\mathrm{S} \cdot \mathrm{C}_{\mathrm{T}} \\
& -\lambda \cdot \mathrm{K}^{\prime} \pm \mathrm{K}_{\mathrm{Q}}+\Delta \mathrm{P}_{\mathrm{a}}+\Delta \ni \mathrm{JB}_{\mathrm{T}} \cdot \mathrm{K}_{\mathrm{T}}
\end{aligned}
$$

Where:

$$
\begin{aligned}
& 2 \sqrt{\mathrm{K}_{\mathrm{d}}-1} \mathrm{~S}= \begin{array}{l}
\text { Compound capacity of the } \\
\text { divider. }
\end{array} \\
& \sqrt{\mathrm{K}_{\mathrm{d}}-1} \mathrm{~S}=\begin{array}{l}
\text { Compound capacity of the } \\
\text { compensating elements. }
\end{array} \\
& \mathrm{C}_{\mathrm{d}}, \mathrm{C}_{\mathrm{K}}, \mathrm{C}_{\mathrm{T}}=\begin{array}{l}
\text { Cost of divider, cost of } \\
\text { compensating element and cost } \\
\text { of step-down transformer. }
\end{array}
\end{aligned}
$$

As it is known from the electrical power systems and the yearly Investment expenses:

$$
\mathrm{C}=\mathrm{C}_{\mathrm{a}}+\mathrm{C}_{\mathrm{Q}} \cdot \mathrm{T}+\mathrm{C}_{\mathrm{n}}
$$

Where:

$$
\begin{aligned}
& \mathrm{C}_{\mathrm{a}}=\begin{array}{l}
\text { Partial expenses on the renovation of } \\
\text { machines. }
\end{array} \\
& \mathrm{C}_{\mathrm{Q} . \mathrm{T}}= \text { Yearly service expenses and } \\
& \text { equipments maintenance. } \\
& \mathrm{C}_{\mathrm{n}}=\text { Yearly expenses for electrical losses. }
\end{aligned}
$$

The basic Capital could be found as per the relation (29), at which the value of coefficient $\lambda$ could be taken from Table (3):

At the beginning, we may neglect the amount $\lambda \mathrm{K}$ and then it will become possible to calculate the basic Capital relative to the capacitive voltage dividers in which their elements of capacitors are as follows:

$$
\mathrm{K}_{\pi}=\sqrt{\mathrm{K}_{\mathrm{d}}-1}\left(2 \beta_{\mathrm{c}}+\beta_{\mathrm{L}}\right) \mathrm{S}+\mathrm{K}_{\mathrm{T}} \cdot \beta_{\mathrm{Q}}\left(\sqrt{\left.\mathrm{K}_{\mathrm{d}}-1-\sin \psi\right)}\right.
$$

Where : $\beta_{c}, \beta_{L}=$ Unity expenses for the capacitor and reactor and it equals:

Table 3: Shows the value of the Coefficient $\lambda$

\begin{tabular}{ll}
\hline Element & $\lambda$ \\
\hline Lightning Arrester for the tension lines & $0.98-0.93$ \\
Connecting capacitors & $0.95-0.9$ \\
Batteries & $0.97-0.9$ \\
The Reactor & $0.95-0.85$ \\
\hline
\end{tabular}

$$
\begin{gathered}
\beta_{\mathrm{c}}=7.2 \mathrm{D} / \mathrm{K} . \mathrm{can} \\
\beta \mathrm{Q}=\text { Unity expenses to compensate the losses of } \\
\text { Reactive capacity: } \\
\beta_{\mathrm{Q}}=2.1^{\mathrm{D}} /_{\mathrm{K} . \text { var }}
\end{gathered}
$$

The converted expenses of the capacitive voltage divider could be determined from the following relation:

$$
\begin{aligned}
\ni= & \left(P_{\mathrm{a}}+\mathrm{P}_{\mathrm{t} . \mathrm{r}} \mathrm{P}_{\mathrm{n}}\right)\left[\sqrt{\mathrm{K}_{\mathrm{d}}-1}\left(2 \beta_{\mathrm{c}}+\beta_{\mathrm{L}}\right)-\right. \\
& \left.\left.\beta_{\mathrm{Q}}\left(\sqrt{\mathrm{k}_{\mathrm{d}}-1}-\sin \psi\right)\right] \mathrm{S}+\mathrm{K}_{\mathrm{T}: \mathrm{r}}\right) \lambda \mathrm{k}^{\prime}+\Delta \mathrm{A} \beta^{\prime}
\end{aligned}
$$

Where,

$$
\begin{gathered}
\mathrm{P}_{\mathrm{a}}, \mathrm{P}_{\mathrm{t} . \mathrm{r}}, \mathrm{P}_{\mathrm{n}}=\begin{array}{l}
\text { The partial expenses on the } \\
\text { renovation and maintenance } \\
\text { affecting the basic capital. }
\end{array} \\
\mathrm{P}_{\mathrm{a}}=0.063, \mathrm{P}_{\mathrm{t} . \mathrm{r}}=0.03, \mathrm{P}_{\mathrm{n}}=0.12, \quad \mathrm{~B}=1.14 \mathrm{D}^{\mathrm{er}} / \mathrm{k}_{\mathrm{w} . \mathrm{h}} \\
\text { AA) THE ELECTRICAL LOSSES } \\
\text { IN THE WORLD }
\end{gathered}
$$

\section{$\triangle A)$ THE ELECTRICAL LOSSES IN THE WORLD}

As per the previous laws and the above mentioned relations, the basic expenses and basic capital for the unity investment expenses of one dividing station rated $60 \mathrm{KVA}$ have been determined. All the results were summarized in the Table 4-7.

The basic capital for the capacitive voltage divider was determined by the following relation:

Table 4: Shows the basic capital, converted expenses and unity expenses of a capacitive dividing station $\mathrm{S}=60 \mathrm{KVA}$ at different voltages

\begin{tabular}{lllll}
\hline High Voltage Line KV & 66 & 132 & 230 & 400 \\
\hline K In Dinar & 2135 & 8190 & 4270 & 6100 \\
In Dinar & 618 & 1052 & 538.2 & 2440 \\
(Dinar/KVA) & 10.3 & 17.5 & 25.6 & 40.6 \\
\hline
\end{tabular}

Table 5: Shows the basic capital, converted expenses and unity expenses of a sub-station $\mathrm{S}=60 \mathrm{KVA}$ at different voltages

\begin{tabular}{lllll}
\hline High Voltage Line KV & 66 & 132 & 230 & 400 \\
\hline K In Dinar & 13536 & 16812 & 28134 & 41411 \\
in Dinar & 2630.4 & 3676.1 & 6045 & 15896 \\
(Dinar/KVA) & 43.8 & 61.26 & 100.73 & 264.9 \\
\hline
\end{tabular}

Table 6: Shows the basic capital, converted expenses and unity expenses when building a cable Line of $10 \mathrm{Km}$ to transmit the power of $\mathrm{S}=60 \mathrm{KVA}$ at different voltages

\begin{tabular}{lllll}
\hline High Voltage Line KV & 66 & 132 & 230 & 400 \\
\hline In Dinar K & 5240 & 6090 & 12440 & 19540 \\
in Dinar & 6288 & 1035 & 2363 & 41034 \\
(Dinar/KVA) & 1048 & 1725 & 393 & 683 \\
\hline
\end{tabular}


Am. J. Applied Sci., 6 (1): 13-23, 2009

Table 7: Shows the basic capital, converted expenses and unity expenses when building an overhead line of $10 \mathrm{Km}$ to transmit the power of $\mathrm{S}=60 \mathrm{KVA}$ at different voltages

\begin{tabular}{lllll}
\hline High Voltage Line KV & 66 & 132 & 230 & 400 \\
\hline In Dinar K & 3490 & 4170 & 8290 & 10010 \\
in Dinar & 5235 & 7089 & 15751 & 21021 \\
(Dinar/KVA) & 872 & 118 & 2625 & 350 \\
\hline
\end{tabular}

$$
\left.\begin{array}{l}
\mathrm{K}_{\mathrm{st}}=2 \beta, \sqrt{\mathrm{k}_{\mathrm{d}}-1} . \mathrm{S} \\
\mathrm{K}_{\mathrm{K}}=\beta_{\mathrm{c}} \sqrt{\mathrm{k}_{\mathrm{d}}}-1 . \mathrm{S}
\end{array}\right\}
$$

While the reactive power induced in the elements of the divider or the required for the divider is determined from the following relation:

$$
\mathrm{Q}=\left(\sqrt{\mathrm{K}_{\mathrm{d}}}-1-\sin \psi\right) \cdot \mathrm{S}
$$

Where: $\psi$ - Angle of the load current which could be found from the following relation:

$$
\begin{aligned}
& \sin \psi=\frac{1}{2 \sqrt{\alpha\left(\mathrm{K}_{\mathrm{d}}-1\right)}} \\
& \alpha=\frac{\beta_{\mathrm{c}}+\beta_{\mathrm{L}}}{\beta_{\mathrm{c}}}
\end{aligned}
$$

From the important economical processes in the electrical system is the converted unity expenses and those which could be found by the following relation :

$$
\zeta=\frac{\ni}{S}
$$

For the Air voltage dividers, we can determine the basic capital from the following relation:

$$
\mathrm{K}_{\pi}=\mathrm{K}_{\mathrm{da}}+\mathrm{K}_{\mathrm{d} 2}+\mathrm{K}_{\mathrm{k}}-\lambda \mathrm{K}^{\prime}-\mathrm{K}_{\mathrm{Q}}
$$

Where it is relatively different from the basic expenses of capacitive voltage dividers, as the basic cost in relation (41) depends on the Isolators and the cost of high voltage lines.

The economical benefit of selecting the way of using lightning arrester line is that it is known that lightning arrester line of a high voltage lines and ultra high voltage is being earthed (lightning arrester linetowers). Ear thing of lightning arrester line in many points (through the towers) makes the electrical losses very high ${ }^{[6,7]}$.

These losses are caused by the current passing to ground through the ring ear thing system, which is generated by the induced voltage because of Electromagnetic Inductance. When hanging two lines for the lightning arrester, these two lines become directly connected through the tower structure, which increases the value of the current, which is passing to ground $^{[8,9,10]}$.

The best and most successful way to reduce these losses is to isolate these lines completely or partially from the ground. The economical and technical benefit of the lightning arrester will increase, when it is used as a source of power to supply the small electrical loads which are far from the main feeding centers that are situated in the field of high voltage lines (66-750) KV. Therefore, it is important to isolate the lightning arrester which is earthed and protecting the high voltage lines.

It should be noted here that the economical benefit will not be high unless the expenses that should be spent to isolate the lightning arrester line from the ground are less than the cost of power loss at the high voltage lines which could be selected to supply the small loads. However, there should be a basic condition for using the isolated lightning arrester for supplying the small loads. This is to protect the high voltage lines from the expected strikes. For this purpose, the lightning arrester line is earthed through a discharge cavity to bypass the strike to the ground before reaching to the point of connecting the load as if this lightning arrester is earthed.

At the lightning arrester line, a voltage is induced which we can find its value as we experienced before by the equation number (15).

In Fig. 4, we introduced the curve which indicates the boundaries of selecting the energy from the high voltage lines by means of the lightning arrester which is used to protect the high voltage lines (110-750) KV. It is clear from the curves that the selected energy from the high voltage lines $330 \mathrm{KV}$ is bigger than that from the high voltage lines of $500 \mathrm{KV}$. This is due to the position of lightning arrester lines relative to the operating lines.

Some of the carried calculations showed that when selecting the energy by means of lightning arrester at seven locations for the high voltage lines and at a distance of $800 \mathrm{Km}$, we will have a selected power of $2000 \mathrm{KVA}$. For the annual peak load equals $\mathrm{T}=3000 \mathrm{~h}$ and 10.42 Million Kilowatt-hour, the economical benefit will be appreciated to select the energy from the lightning arrester line having a rate of 20 Derham / kWHour which is around 2.08 Libyan Dinar yearly from the strikes. This leads us to the following conclusion:

When isolating the lightning arrester line from the ground, the additional losses will be reduced by 1.8 
times. This amount is possible to be used as main or back up power source to supply the loads existing within the field of the high voltage lines and far from the main feeding centers (i.e. Military centers, Signalboosting stations, Petrol stations... etc).

\section{CONCLUSION}

In this research, an analysis of the electrical distribution system in the Republic was made, specially the demand on the electrical energy where there is a possibility to supply some loads by selecting the energy from the high voltage lines by means of the different voltage dividers:

- The best way from the economical point of view to supply the small loads which are far from the main feeding centers and exist within the field of high voltage lines is to use the lightning arrester line and the voltage divider through the capacitors.

- The applied voltage on the lightning arrester line isolated from the ground is directly proportional with the voltage of the high tension line and don't depend on the frequency of the alternating current or the selected power by its means.

- When using the lightning arrester, the voltage applied on it will increase as much as the voltage of the high tension line is increasing and the displacement between lightning arrester and the high tension lines is decreasing.

- In Libya, due to its circumstances we see that the economical processes of the non-traditional ways (Lightning Arrester) to supply the small loads far from the main feeding centers are much better than the economical processes of the traditional ways (Power Transformers) to supply the same loads.

- The additional losses in the high tension lines could be remarkably reduced when isolating the lightning arrester line for particular distances.

\section{REFERENCES}

1. Bulashevich, D.H. and V. Yorinkov, 1959. The power selection from transmission lines by using especial condensers substation. Moscow, pp: 135.

2. Tarassof, A. and V. Babrofsky, 1961. The application of reactor to select the power from transmission lines. Power Station Magazine, No.3.

3. Capacitor bank used to power remote loads can be a headache, Electrical world 1971, MAY15, pp: 48.

4. Yorinkov, V.D., 1948. The substation with inductance voltage divider. Electricity J. No 9.

5. Odeh, H.B., 1992. Principles of Investing the Electrical Network. MINSK.

6. Odeh, H.B., 1992. Voltage Dividers TechnologyEnergy Magazine, 4: 22-28.

7. Yourenskof, F.A., 1985. Capacitive Voltage Dividers. the Energy, Moscow.

8. Odeh, H.B. and I. Al-Ajtal, 1992. Calculating the Displacement Current in the Field of High Voltage Lines. The Scientific Magazine, 3.

9. Staif, I., 1982. The High Tensions and Methods to Protect from, Halab.

10. Mohammad, H. and Y. El-Tous, 2003. Introduction in Analyzing Faults and Protecting the Electrical Power Systems. Amman. 